\title{
https://doi.org/10.46813/2021-132-043 \\ EFFECT OF DEFECTS ORIGINATING UNDER THE PROTON IRRADIATION ON THE ELECTROPHYSICAL AND DETECTOR PROPERTIES OF CdTe:CI AND CdZnTe
}

\author{
A.I. Kondrik \\ National Science Center "Kharkov Institute of Physics and Technology", \\ Kharkiv, Ukraine \\ E-mail:kondrik@kipt.kharkov.ua
}

\begin{abstract}
The work is dedicated to studying by computer modeling the mechanisms of the influence of radiation defects, originating under high energy proton irradiation, on the resistivity $\rho$, lifetime of nonequilibrium electrons $\tau_{n}$ and holes $\tau_{p}$ in $\mathrm{CdTe}: \mathrm{Cl}$ and $\mathrm{Cd}_{0.9} \mathrm{Zn}_{0.1} \mathrm{Te}$, and charge collection efficiency $\eta$ of room temperature ionizing radiation detectors based on these materials. The effect of recombination at deep levels of radiation defects on the degradation of $\tau_{n}, \tau_{p}$, and $\eta$ of detectors based on $\mathrm{CdTe}: \mathrm{Cl}$ and $\mathrm{Cd}_{0.9} \mathrm{Zn}_{0.1}$ Te was studied. Energy levels of radiation defects also substantially effect on compensation degree of semiconductor decreasing $\rho$. The main factors affecting the abrupt or gradual decrease in the resistivity and charge collection efficiency of these detectors during their bombardment by high-energy protons, leading to complete degradation of their recording ability, were found. The important role of purity and deep donor concentration in initial state of the detector material was indicated.
\end{abstract}

PASC: 61.80.-x; 61.82.Fk; 87.66.Pm

\section{INTRODUCTION}

CdTe and CdZnTe are traditionally considered as semiconductor materials for X-ray and gamma-ray high energy resolution detectors operating at room temperature. At present the detectors have been developed for industrial tomography and astrophysics, as well as for medical imaging equipment. Ions irradiation can generate electron-hole pairs in semiconductors, and the above-mentioned materials are also considered as very promising those for the manufacture of charged particle detectors [1-3]. Even high-energy charged particles in semiconductors have short mean free paths, not exceeding several tens of microns, therefore the preferential collection of single charge carrier, which is necessary to get high energy resolution $[4,5]$, can be easily achieved.

Semiconductor charged particle detectors are intended to operate under the influence of a harsh radiation environment, for example, under proton irradiation inducing radiation defects in the matrix, which affect the electrophysical properties and detector performance. Elucidation of the mechanisms of such influence is of decisive importance to apply the detectors in various fields, as well as to improve the methods of radiation monitoring. Earlier studies of radiation damage caused by charged particles such as protons in $\mathrm{CdTe}$ and $\mathrm{CdZnTe}$ detectors were mainly devoted not to studying the mechanisms of the influence of radiation defects energy levels on the detector properties, but to investigations of the effect of the radiation doses on the device characteristics [2, 6-14], the most important are the charge collection efficiency, resistivity, electron mobility, lifetimes of nonequilibrium electrons, and holes. For example, Yaxu $\mathrm{Gu}$ et al. [13] found that a high density of nonradiative recombination centers is generated in CdZnTe crystals after $2 \mathrm{MeV}$ proton fluence of $6 \cdot 10^{13} \mathrm{p} / \mathrm{cm}^{2}$, which causes a significant deterioration in the detector performance. Similar results were reported in paper
[14], where the charge collection of CdZnTe-based detector significantly degraded after irradiation of $2 \mathrm{MeV}$ proton fluences of above $3.3 \cdot 10^{11} \mathrm{p} / \mathrm{cm}^{2}$. Zanarini et al. [10] investigated damages caused by $2 \mathrm{MeV}$ protons in $\mathrm{CdZnTe}$ and $\mathrm{CdTe}$ radiation detectors, and found that $\mathrm{CdZnTe}$ detectors have decreased performance after a fluence of $2.6 \cdot 10^{11} \mathrm{p} / \mathrm{cm}^{2}$ which about an order of magnitude higher than limiting dose for CdTe-based detectors. The distribution of the charge collection efficiency $\eta$ over the cathode surface of a CdZnTe detector bombarded with $2 \mathrm{MeV}$ protons was estimated in paper [2], using ion beam induced charge microscopy. It was found that the bombardment of selected areas of the surface with a fluence of $10^{5} \mathrm{ion} / \mathrm{cm}^{2}$ causes structural damage in the irradiated areas and a noticeable deterioration of the charge collection efficiency.

The authors of paper [12] found that the fluence of $700 \mathrm{keV}$ protons, which caused a complete degradation of the characteristics of CdTe and CdZnTe detectors, was identified to be the same for investigated detectors i.e. $2 \cdot 10^{12} \mathrm{p} / \mathrm{cm}^{2}$, even if batches of detectors characterized by different initial transport properties had been chosen. The transport properties of the detectors were studied by measuring the product of the mobility by the lifetime of nonequilibrium charge carriers. The photoinduced current transient spectroscopy (PICTS) analysis was used to determine the activation energy of deep traps present in the materials. It was also suggested in [12] that some deep levels, which serve as traps for nonequilibrium electrons and holes, play an important role in changing the detector performance during irradiation. The CdTe and CdZnTe detector materials have a high resistivity of $10^{10} \ldots 10^{11} \Omega \cdot \mathrm{cm}$, which greatly complicates or makes it impossible, basing only on experimental techniques, to elucidate the mechanisms of change and degradation of the electrophysical and detector properties under the influence of radiation defects. In this regard, it is very important to use the computer modeling as an additional 
research tool, based on known experimental results and proven physical models.

The aim of this work is to study by the simulation method the effect of radiation defects arising under the proton irradiation on the mechanisms of degradation of the electrophysical and detector properties of CdTe:Cl and $\mathrm{CdZnTe}$. The calculations were made for the electron mobility $\mu_{n}$, the resistivity $\rho$, the lifetime of nonequilibrium electrons $\tau_{n}$, and holes $\tau_{p}$, the charge collection efficiency $\eta$ depending on the concentration of doping shallow donors $N_{d}$ for different defect compositions of the samples before and after proton irradiation.

\section{PHYSICAL MODELS AND MATERIALS COMPOSITION}

The applied models as well as their testing were described in detail in [15], and the spectral characteristics of the initial and irradiated $\mathrm{CdTe}: \mathrm{Cl}$ and $\mathrm{Cd}_{0.9} \mathrm{Zn}_{0.1}$ Te were taken from $[10,12,13]$. To determine the Fermi level $F$ and the concentrations of free electrons $n$ and holes $p$ in the parabolic band approximation, we used a multilevel compensation model for an arbitrary number of impurities and defects with construction and numerical solution of the corresponding electroneutrality equation taking into account all impurities and defects experimentally recorded in $[12,13]$. The electron mobility $\mu_{n}$ was calculated using the approximation of the pulse relaxation time and taking into account the mechanisms of scattering at ionized and neutral centers, acoustic, piezoelectric, and optical phonons. The hole mobility $\mu_{p}$ was considered unchanged and equal to $70 \mathrm{~cm}^{2} /(\mathrm{V} \cdot \mathrm{s})$. Specific conductivity was determined as a quantity consisting of electron and hole components, and it was calculated by the formula: $e \cdot n \cdot \mu_{n}+e \cdot p \cdot \mu_{p}$, where $e$ is the electron charge. Resistivity was calculated as the reciprocal of conductivity. The lifetimes of nonequilibrium electrons and holes were calculated using the Shockley-Reed-Hall recombination model, and the charge collection efficiency of the detector was determined according to the Hecht equation [16, p. 489]. The experimentally measured and published values of the ith energy levels of defects $E_{i}$, their concentration $N_{i}$, and the capture cross section $\sigma_{i}$ of nonequilibrium charge carrier traps were used as input parameters. As in [12], the distance between the detector electrodes was assumed to be $1 \mathrm{~mm}$, and the electric field strength for $\mathrm{CdTe}: \mathrm{Cl}$-based detector was $500 \mathrm{~V} / \mathrm{cm}$, and for CdZnTe-based that did $1000 \mathrm{~V} / \mathrm{cm}$.

The typical initial composition of the unirradiated CdTe: $\mathrm{Cl}$ and $\mathrm{Cd}_{0.9} \mathrm{Zn}_{0.1}$ Te detector materials, registered in [12], is presented in the Table. Since the PICTS technique used in that paper to determine the compositions of the samples allows one to measure accurately only the energy of defects, the concentrations of impurities and defects were determined by us in such a way as to provide hole conductivity as well as the known maximum values of resistivity $\rho=10^{10}$ and $10^{11} \Omega \cdot \mathrm{cm}$ for CdTe: $\mathrm{Cl}$ and $\mathrm{Cd}_{0.9} \mathrm{Zn}_{0.1}$ Te respectively. In addition to [12], a similar composition was described, for example, in [17-20], where, as a rule, A centers were present, for which a doping donor was introduced to compensate. Aluminum, indium, yttrium can be used as a shallow dopant donor in CdZnTe, while chlorine is often doped in CdTe.

Composition of defects in CdTe: $\mathrm{Cl}$ and $\mathrm{Cd}_{0.9} \mathrm{Zn}_{0.1}$ Te before irradiation

\begin{tabular}{|c|c|c|c|c|c|c|}
\hline \multirow{2}{*}{ Defect } & \multicolumn{2}{|c|}{ Energy levels $E_{i}, \mathrm{eV}$} & \multicolumn{2}{|c|}{ Concentrations $N_{i}, \mathrm{~cm}^{-3}$} & \multicolumn{2}{|c|}{$\begin{array}{c}\text { Capture cross-sections } \\
\sigma_{\mathrm{i}}, \mathrm{cm}^{2} \\
\end{array}$} \\
\hline & CdTe:Cl & $\mathrm{Cd}_{0.9} \mathrm{Zn}_{0.1} \mathrm{Te}$ & CdTe:Cl & $\mathrm{Cd}_{0.9} \mathrm{Zn}_{0.1} \mathrm{Te}$ & CdTe:Cl & CdZnTe \\
\hline $\mathrm{AX}^{-}$ & 0.11 & - & $3.3 \cdot 10^{14}$ & - & $1.7 \cdot 10^{-21}$ & - \\
\hline $\mathrm{A}^{-}$ & 0.12 & - & $2 \cdot 10^{15}$ & - & $3.6 \cdot 10^{-21}$ & - \\
\hline $\mathrm{A}^{-}$ & \multicolumn{2}{|c|}{0.14} & $2 \cdot 10^{15}$ & $2 \cdot 10^{15}$ & \multicolumn{2}{|c|}{$1.8 \cdot 10^{-19}$} \\
\hline $\mathrm{A} 1^{-}$ & \multicolumn{2}{|c|}{0.16} & $2 \cdot 10^{15}$ & $2 \cdot 10^{15}$ & \multicolumn{2}{|c|}{$4 \cdot 10^{-19}$} \\
\hline $\mathrm{K}^{-}$ & - & 0.23 & - & $6 \cdot 10^{15}$ & - & $6 \cdot 10^{-19}$ \\
\hline $\mathrm{X}^{-}$ & \multicolumn{2}{|c|}{$\frac{1}{0.29}$} & $2 \cdot 10^{15}$ & $6 \cdot 10^{15}$ & $3.6 \cdot 10^{-19}$ & $4.0 \cdot 10^{-19}$ \\
\hline $\mathrm{D}^{2-}$ & \multicolumn{2}{|c|}{0.41} & $2 \cdot 10^{15}$ & $2 \cdot 10^{15}$ & \multicolumn{2}{|c|}{$7.0 \cdot 10^{-17}$} \\
\hline $\mathrm{Z}^{+}$ & $\begin{array}{c}1.05 \\
\left(\mathrm{E}_{\mathrm{c}}-0.47\right)\end{array}$ & $\begin{array}{c}1.05 \\
\left(\mathrm{E}_{\mathrm{c}}-0.52\right)\end{array}$ & $1 \cdot 10^{14}$ & $1 \cdot 10^{15}$ & \multicolumn{2}{|c|}{$5.0 \cdot 10^{-17}$} \\
\hline $\mathrm{J}^{-}$ & \multicolumn{2}{|c|}{0.53} & $2 \cdot 10^{15}$ & $5.0 \cdot 10^{14}$ & \\
\hline $\mathrm{Y}^{-}$ & \multicolumn{2}{|c|}{0.63} & $1.8 \cdot 10^{15}$ & $8.0 \cdot 10^{15}$ & \multicolumn{2}{|c|}{$3.2 \cdot 10^{-17}$} \\
\hline $\mathrm{W}^{-}$ & \multicolumn{2}{|c|}{0.70} & $1.5 \cdot 10^{15}$ & $9.0 \cdot 10^{15}$ & $1.3 \cdot 10^{-17}$ & $1.3 \cdot 10^{-18}$ \\
\hline $\mathrm{H}^{-}$ & 0.75 & - & $2.0 \cdot 10^{15}$ & - & $1.0 \cdot 10^{-18}$ & - \\
\hline $\mathrm{H} 1^{+}$ & $0.73\left(\mathrm{E}_{\mathrm{c}}-0.79\right)$ & $0.75\left(\mathrm{E}_{\mathrm{c}}-0.82\right)$ & $4.0 \cdot 10^{15}$ & $7.0 \cdot 10^{15}$ & $2.0 \cdot 10^{-17}$ & $4,0 \cdot 10^{-18}$ \\
\hline $\mathrm{I}^{+}$ & $0.52\left(\mathrm{E}_{\mathrm{c}}-1.0\right)$ & $0.57\left(\mathrm{E}_{\mathrm{c}}-1.0\right)$ & $5 \cdot 10^{15}$ & $6.0 \cdot 10^{15}$ & \multicolumn{2}{|c|}{$1.0 \cdot 10^{-18}$} \\
\hline
\end{tabular}

There are also deep acceptors - cadmium vacancies $V_{\mathrm{Cd}}$ and deep donors in the form of tellurium at site of cadmium $\mathrm{Te}_{\mathrm{Cd}}$. The presence of deep donors in the matrix is necessary to achieve the high resistance state required for the operation of detectors.
The first column of the Table contains the symbols and charge states of defects: 'plus' for electron traps, and 'minus' for hole traps. The designations of defects in this column are the same as in [12]. Energy levels are measured from the valence band. Additionally, the 
energy levels relative to the conduction band for donor centers are indicated in parentheses. The Table also lists the values of the level capture cross sections $\sigma_{i}$, the order of magnitude of which was determined in [21], where the contribution of all levels to the currents emitted into the corresponding bands was taken into account. The designations of defects and their probable nature are given in papers [10-12, 18-21]. Dopants of a shallow donor introduced into the matrix of the studied materials are intended to compensate shallow acceptors $(\mathrm{AX}, \mathrm{A} 0, \mathrm{~A}, \mathrm{~A} 1)$ and to achieve a high-resistance state necessary for the operation of detectors. It is generally accepted today that the levels AX, A0, A, A1, K, X are the complexes of cadmium vacancies with dopants and background impurities. The cadmium vacancy apparently corresponds to defect $\mathrm{D}$ [22]. The donor defects $\mathrm{Z}\left(\mathrm{E}_{\mathrm{c}}-0.47 \mathrm{eV}\right.$ in $\mathrm{CdTe}, \mathrm{E}_{\mathrm{c}}-0.52 \mathrm{eV}$ in $\left.\mathrm{CdZnTe}\right)$ and $\mathrm{H} 1\left(\mathrm{E}_{\mathrm{c}}-0.79 \mathrm{eV}\right.$ in $\mathrm{CdTe}, \mathrm{E}_{\mathrm{c}}-0.82 \mathrm{eV}$ in $\left.\mathrm{CdZnTe}\right)$ can be $\mathrm{Te}(\mathrm{I})$ and $\mathrm{Te}_{\mathrm{Cd}}$ respectively. Donor defect I corresponds to a tellurium vacancy. The nature of the remaining defect levels has not yet been fully elucidated.

\section{RESULTS AND DISCUSSION}

The authors of paper [12] irradiated $\mathrm{CdTe}: \mathrm{Cl}$ and $\mathrm{Cd}_{0.9} \mathrm{Zn}_{0.1} \mathrm{Te}$ detectors with $700 \mathrm{keV}$ protons and fluences from $2.5 \cdot 10^{11}$ to $2 \cdot 10^{12} \mathrm{p} / \mathrm{cm}^{2}$. After irradiation of cadmium telluride detector with a fluence of $2 \cdot 10^{12} \mathrm{p} / \mathrm{cm}^{2}$, the charge collection and the value of the product of the electron mobility $\mu_{n}$ by the lifetime of nonequilibrium electrons $\tau_{n}$ decreased by 13.5 times. To investigate this behavior, an analysis was performed using PICTS technique. The PICTS spectra, given in [12] for the initial and irradiated materials, were used in present work for a model study of changes in the electrophysical and detector properties of $\mathrm{CdTe}: \mathrm{Cl}$ and $\mathrm{Cd}_{0.9} \mathrm{Zn}_{0.1}$ Te during proton bombardment.

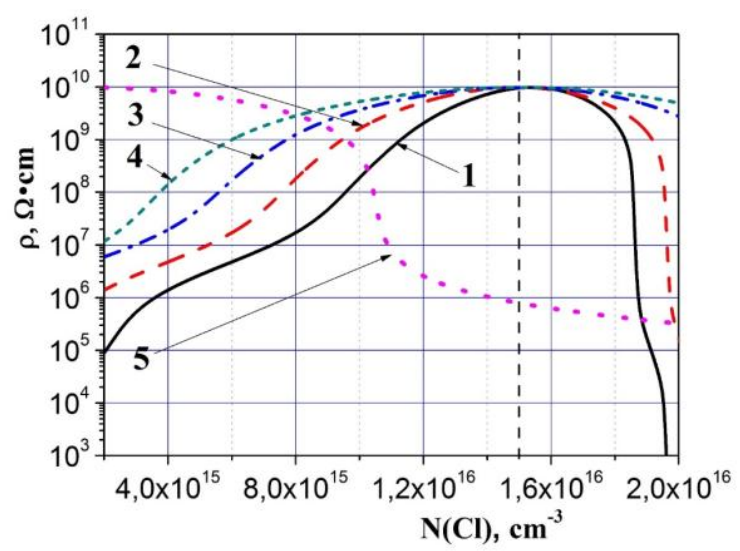

Fig. 1. Dependences of the specific resistance of CdTe:Cl on the chlorine concentration for the different defect concentrations $N, \mathrm{~cm}^{-3}$, and after various fluences of protons $J_{p}, p / \mathrm{cm}^{2}: 1$ - the initial sample with the composition given in the table; $2-J_{p}=2,5 \cdot 10^{11}$, $N(Y)=1.8 \cdot 10^{15}, N(H)=3 \cdot 10^{15}, N(H 1)=6 \cdot 10^{15}$; $3-J_{p}=6 \cdot 10^{11}, N(Y)=1.9 \cdot 10^{15}, N(H)=5 \cdot 10^{15}$, $N(H 1)=8 \cdot 10^{15} ; 4-J_{p}=1.2 \cdot 10^{12}, N(Y)=2.0 \cdot 10^{15}$, $N(H)=7 \cdot 10^{15}, N(H 1)=1 \cdot 10^{16} ; 5-J_{p}=2 \cdot 10^{12}$, $N(Y)=1.9 \cdot 10^{15}, N(H)=5 \cdot 10^{15}, N(H 1)=8 \cdot 10^{15}$, $N(Z)=1 \cdot 10^{16}$. The vertical dashed line corresponds to the studied sample
Fig. 1 shows the dynamics of the change in the resistivity of $\mathrm{CdTe}: \mathrm{Cl}$ depending on the concentration of the chlorine dopant after various proton irradiation fluxes $J_{p}$. The range of variation of the $\mathrm{Cl}$ dopant concentration was chosen so that for an unirradiated material the resistivity dependence passed through a maximum. The vertical dashed line intersects this $\rho$ dependence near the maximum, marks the chlorine concentration on the horizontal axis, at which hole conductivity is observed in cadmium telluride, and therefore can denote the material under study. According to the spectra given in [12], during irradiation the concentrations of defects $\mathrm{Z}(0.47 \mathrm{eV})$, $\mathrm{Y}(0.63 \mathrm{eV}), \mathrm{H}(0.75 \mathrm{eV}), \mathrm{H} 1(0.79 \mathrm{eV})$ increase, and the authors of this paper supposed that defects $\mathrm{Z}$ and $\mathrm{H} 1$ are the only candidates which cause degradation of electron transport properties. Moreover, the appearance and increase in the content of the donor defect $\mathrm{Z}$ always causes a complete degradation of the detector properties of CdTe:Cl. All these circumstances were taken into account when simulating changes in $\rho$ during irradiation, shown in Fig. 1. It can be seen from the figure that with an increase in the content of radiation defects, the resistivity $\rho$ first stabilizes together with an expansion of the $\mathrm{Cl}$ concentration range where a highresistance state is reached, and then there is a sharp drop in the resistivity by about four orders of magnitude, which leads to a complete degradation of the detector properties.

The fact of an abrupt deterioration of the detector properties was established experimentally in [12] (see Fig. 1 [12]). There it was shown that after the fluence of $2 \cdot 10^{12} \mathrm{p} / \mathrm{cm}^{2}$ the gamma spectrum of CdTe:Cl-based detector from the ${ }^{57} \mathrm{Co}$ demonstrates drastically degradation of collecting properties. According to the simulation performed in present work, the reason for such a jump in properties is the appearance in large quantities of a radiation defect $\mathrm{Z}$ which pulls the Fermi level closer to the conduction band, thereby increasing the concentration of free electrons and decreasing $\rho$. The behavior of the Fermi level $F$ is shown in Fig. 2.

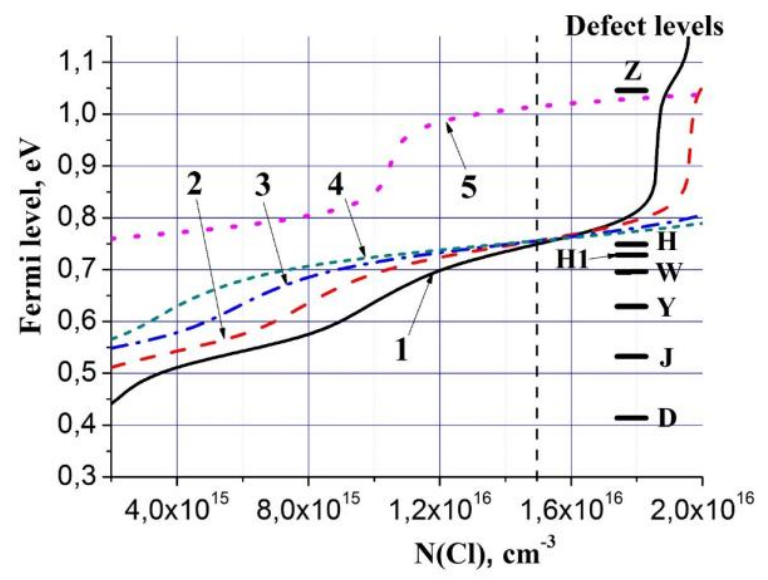

Fig. 2. Behavior of the Fermi level, measured from the valence band, as a function of the concentration of the doping chlorine after various proton fluences. The fluences and defect concentrations are the same as for the numbered curves in Fig. 1. The vertical dashed line corresponds to the studied sample 
We see for curves 1-4 the pinning of Fermi level near the middle of the band gap and, hence, the stabilization of $\rho$, which occurs due to a large increase in the concentration of acceptor defects $\mathrm{H}$, especially donor H1 (see Fig. 2 [12]), the energy levels of which attract $F$. A gradual increase in the concentrations of donor radiation defects $\mathrm{Z}$ and $\mathrm{H} 1$ increases the number of electrons $n$ in the conduction band. Finally, at certain concentrations of $\mathrm{Z}$ and $n$, a sharp displacement of $F$ to the vicinity of level $\mathrm{Z}$ occurs (see Fig. 2, curve 5).

After an abrupt displacement of the Fermi level to the vicinity of $\mathrm{Z}$, the energy level of which becomes partially ionized, a recombination of nonequilibrium electrons at this level occurs, which, in turn, reduces the charge collection efficiency $\eta$ and further deteriorates the detector properties.

Fig. 3 shows the dynamics of changes in charge collection efficiency during the proton bombardment. Here for dependencies 1-4, the concentration of $\mathrm{Z}$ $\left(10^{13} \mathrm{~cm}^{-3}\right)$ is much lower than the content of any impurities and defects. For curves 5-7, the concentration of $\mathrm{Z}$ gradually increases, which causes a noticeable decrease in charge collection due to recombination at the $Z$ level of nonequilibrium electrons, which, together with the influence of $\mathrm{Z}$ on a sharp decrease in $\rho$, clearly demonstrates the wellknown experimental fact about the decisive role of this defect in degradation detector properties of $\mathrm{CdTe}: \mathrm{Cl}$. Based on the character of dependences 1-4 in Fig. 3, we see that the charge collection for the investigated detector material changes little. The reason of this effect is the small variability of the position of the Fermi level (see Fig. 2) before the appearance of a defect $\mathrm{Z}$ in an appreciable amount and, therefore, the little variability of the ionization degree of energy levels close to $F$, which capture nonequilibrium charge carriers.

Simulation also showed that the main contribution to the degradation of charge collection is made by a decrease in the lifetime of nonequilibrium electrons $\tau_{n}$ by more than an order of magnitude. At the same time, the lifetime of nonequilibrium holes $\tau_{p}$ is reduced by less than two times.

Thus, the reason for the experimentally observed in a number of cases a sharp degradation of the detector properties of $\mathrm{CdTe}: \mathrm{Cl}$ after a certain dose of proton irradiation should be considered the appearance in a large amount of donor radiation defect, presumably tellurium interstitial Te (I), the energy level of which located in the upper half of the band gap. The emergence of $\mathrm{Te}$ (I) and a noticeable increase of its concentration is accompanied by a jump in the Fermi level $F$ to the upper half of the band gap with a change in conductivity from hole to electronic and a sharp drop in the resistivity, which is the main reason of detector degradation. To increase the radiation resistance of $\mathrm{CdTe}: \mathrm{Cl}$, it is necessary to stabilize the position of the Fermi level during irradiation, which can be achieved by the formation of a sufficient amount of deep acceptor with energy level located below the middle of bang gap. Such deep acceptor is cadmium vacancy $V_{\mathrm{Cd}}$ not bound in complexes with background and dopant impurities. The formation of such complexes is characterized by an increase in the charge number of cadmium vacancies from ${ }^{-2} V_{\mathrm{Cd}}$ to ${ }^{-1} V_{\mathrm{Cd}}$ or ${ }^{0} V_{\mathrm{Cd}}$, and, as a consequence, a decrease in their effect on the Fermi level. To restrict the formation of these complexes, the purity of the detector material should be increased, and the concentration of doping shallow donors should be reduced to some value.

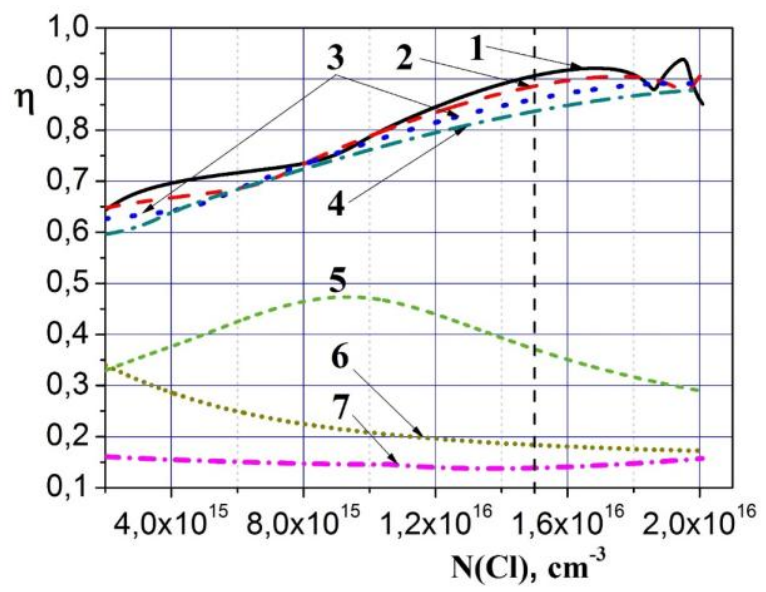

Fig. 3. Dependences of the charge collection efficiency on the concentration of doping chlorine after bombardment by protons with different fluences. The sample characteristics for 1-5 curves are the same that for numbered curves in Fig. $1 ; 6-N(Z)=3 \cdot 10^{16} \mathrm{~cm}^{-3}$;

\section{$7-N(Z)=4 \cdot 10^{16} \mathrm{~cm}^{-3}$. The vertical dashed line} corresponds to the studied sample

Now we consider the results of modeling changes in the electrophysical and detector properties of CdZnTe under the influence of proton irradiation, experimentally investigated in [12], where two batches of samples no. 1 and 2 were irradiated with the same proton fluence as $\mathrm{CdTe}: \mathrm{Cl}$ discussed above. Samples of batch no. 1 at first did not change their properties during irradiation, and then at a final stage suddenly deteriorated the detector properties after a fluence of $2 \cdot 10^{12} \mathrm{p} / \mathrm{cm}^{2}$. We have already considered above a similar effect by the example of CdTe:Cl in which almost the same defects and energy levels were registered, as shown in the Table. On the contrary, detectors of batch no. 2 gradually lost their registering properties during irradiation, so we will first consider this specific case.

It follows from the PICTS spectra, shown in Fig. 5 of paper [12], that in the process of proton bombardment, only the relative content of radiation defects $\mathrm{K}(0.23 \mathrm{eV})$ and $\mathrm{X}(0.29 \mathrm{eV})$ increases noticeably, and a some concentration of these defects already occurs in the initial $\mathrm{Cd}_{0.9} \mathrm{Zn}_{0.1}$ Te (Fig. 4 [12]). For this reason, the calculations were carried out taking into account the gradual increase in the content of $\mathrm{K}$ and $\mathrm{X}$ during irradiation. Fig. 4 shows the dependences of the change in the resistivity (a) and the charge collection efficiency (b) of CdZnTe-based detectors on the concentration of doping shallow donor for unirradiated sample and with different concentrations of radiation defects K, X. Curves 5 in both plots approximately correspond to the state of the detector after the proton fluence of $2 \cdot 10^{12} \mathrm{p} / \mathrm{cm}^{2}$ with complete degradation of registering properties. It can be seen that, as in the experiment of paper [12], there is a gradual degradation of the detector properties of CdZnTe. We will try to 
understand the reasons for this phenomenon. Let us consider the behavior of the Fermi level shown in Fig. 5, which also shows the defects levels with the exception of the donor defect I (tellurium vacancy), the level of which practically coincides with the level of the acceptor defect $\mathbf{J}$.

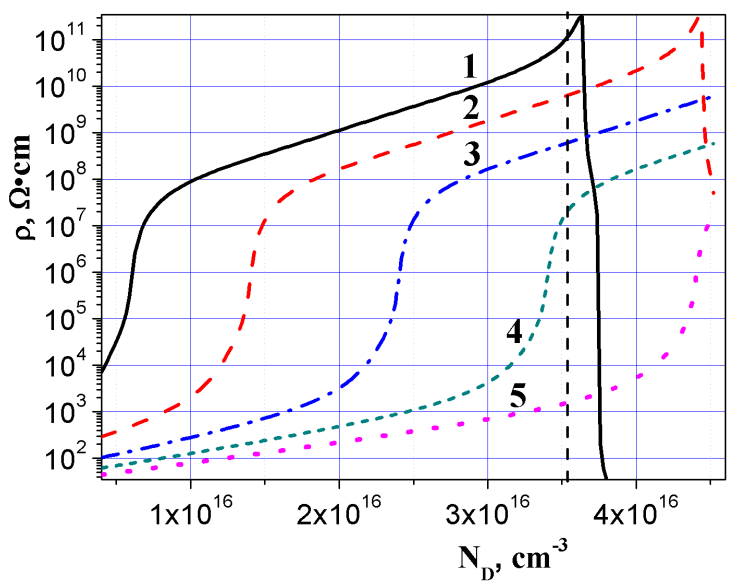

$a$

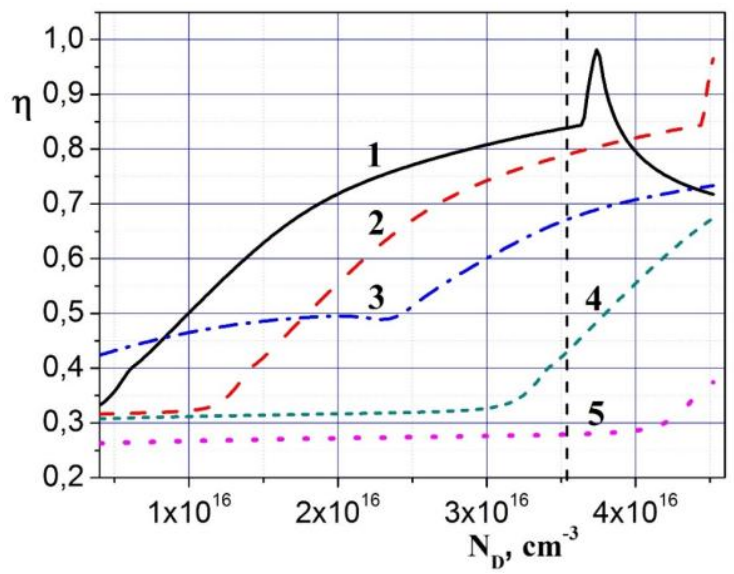

$b$

Fig. 4. Dependences of the resistivity (a) and the charge collection efficiency $(b)$ in a $C d_{0.9} Z n_{0.1}$ Te detector on the content of doping shallow donors for different concentrations of $K$ and $X$ defects $N(K, X), \mathrm{cm}^{-3}$. 1 - initial, unirradiated sample, $6 \cdot 10^{15} ; 2-1 \cdot 10^{16}$; $3-1.5 \cdot 10^{16} ; 4-2 \cdot 10^{16} ; 5-2.5 \cdot 10^{13}$.

The vertical dashed lines denote the sample under study

For the material under study, the maximum values of the resistivity and charge collection, required for the operation of the detectors, are observed at the Fermi level position $F \sim 0.8 \mathrm{eV}$, i.e. in the vicinity of the deep donor level of $\mathrm{H} 1$, which, by the opinion of the most investigators, is the substitutional defect $\mathrm{Te}_{\mathrm{Cd}}[20,23$, 24]. During the proton bombardment, carried out by the authors of paper [12], the interstitial tellurium $\mathrm{Te}(\mathrm{I})^{2+}$, $T e_{\mathrm{Cd}}^{+}$, and also cadmium vacancies $V_{\mathrm{Cd}}^{2-}$ are formed; the last form complexes $\mathrm{K}$ and $\mathrm{X}$ with various background impurities. Apparently, the latter mechanism turned out to be predominant, which led to the prevailing formation of radiation defects $\mathrm{K}$ and $\mathrm{X}$ of the acceptor type. As the concentrations of $\mathrm{K}$ and $\mathrm{X}$ increase, they begin to shift gradually the Fermi level $F$ towards the valence band with a gradual decrease in the resistivity. In this case, a jump in the position of $F$, and hence $\rho$, as it was for $\mathrm{CdTe}: \mathrm{Cl}$, does not occur, since the Fermi level in its drift gradually passes by the levels W, Y, J, D, I which prevent abrupt changes of $F$ position. In the vicinity of each of these levels, within a certain range of concentrations of radiation defects, the Fermi level changes small, i.e. some pinning effect takes place, and it has a stabilizing effect.

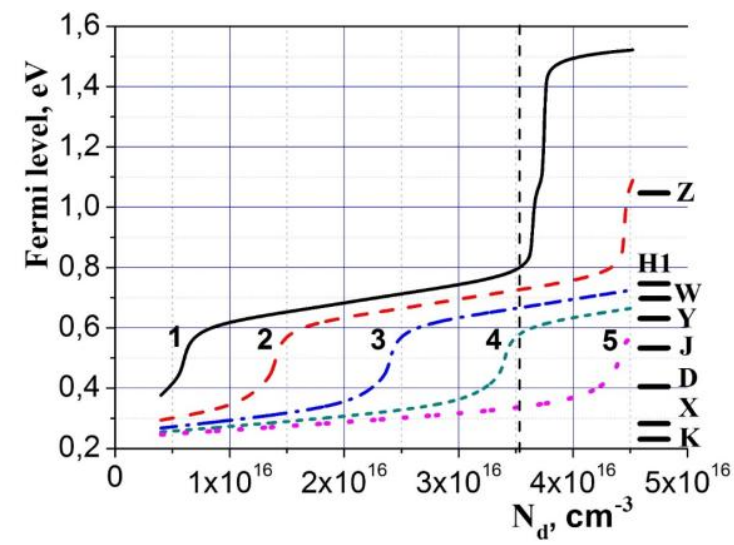

Fig. 5. Dependences of the Fermi level on the concentration of a doping shallow donor for different contents of radiation defects $K$ and $X$, the concentrations of which are the same as for numbered curves 1-5 in Fig. 4. The vertical dashed line denotes the sample under study

In addition, partially ionized levels (W, Y, J, D, I) serve as centers of recombination of nonequilibrium charge carriers. As the Fermi level drifts during irradiation, the concentration of the radiation centers of recombination increases. Ultimately, the Fermi level is fixed near the $\mathrm{K}$ and $\mathrm{X}$ levels, which is accompanied by a decrease in the resistivity by several orders of magnitude, as well as a decrease in charge collection by a factor of two to three compared to the initial state due to the recombination at these levels. $\mathrm{K}$ and $\mathrm{X}$ levels are of the acceptor type; therefore, they are traps for holes, and it was just experimentally confirmed in [12]. The behavior of the Fermi level in CdTe: $\mathrm{Cl}$ (see Fig. 2) is completely different from that just described. In $\mathrm{CdTe}: \mathrm{Cl}$, with an increase in the concentration of the radiation defect $\mathrm{Z}$ during irradiation, there are no other defect levels near which the level $F$ could be pinned along the path of its displacement towards the level $\mathrm{Z}$ in the band gap, therefore, precisely a jump of the Fermi level took place, and a sharp degradation of detector properties was experimentally observed.

In [12], the batch of CdZnTe samples no. 1 was also investigated, which after a proton flux $J_{p}=2 \cdot 10^{12} \mathrm{p} / \mathrm{cm}^{2}$ demonstrated an abrupt degradation of the detector properties. However, the PICTS spectra of these samples after irradiation are not presented in the article; therefore, it is difficult for them to indicate the degradation mechanism. Nevertheless, in paper [10] where the damage caused by $2 \mathrm{MeV}$ protons in CdTe and CdZnTe radiation detectors was investigated, the gamma spectra of $\mathrm{Cd}_{0.9} \mathrm{Zn}_{0.1}$ Te detector from the ${ }^{57} \mathrm{Co}$ source (see Fig. 4 [10]) are presented, and one can see sharp deterioration of the detector properties after the fluence $(2.1+2.6) \cdot 10^{11} \mathrm{p} / \mathrm{cm}^{2}$. In this case, the PICTS spectra for $\mathrm{Cd}_{0.9} \mathrm{Zn}_{0.1} \mathrm{Te}$ are presented (see Fig. 5 in 
[10]), in which it can be seen that a defect $Z$ appears in a completely degraded material, at that in a large amount. Thus, it can be assumed that in the batch samples of $\mathrm{Cd}_{0.9} \mathrm{Zn}_{0.1}$ Te no.1 of paper [12], a sharp degradation of the detector properties occurred due to a jump-like transition of the Fermi level to the vicinity of the donor level $\mathrm{Z}$ located in the upper half of the band gap.

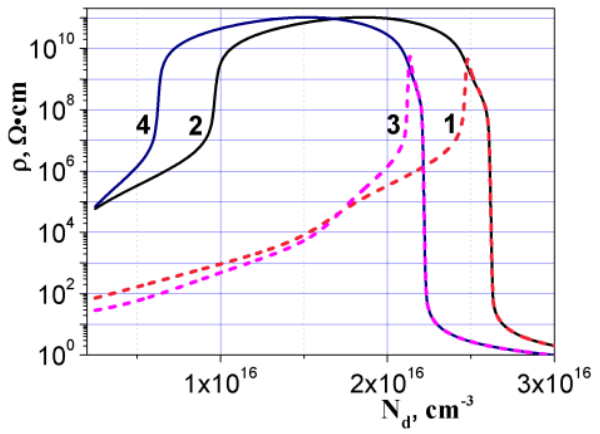

$a$

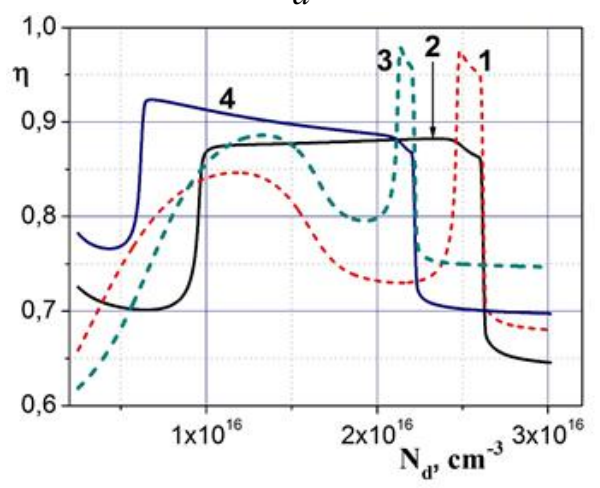

$b$

Fig. 6. Dependences of resistivity (a) and charge collection efficiency $(b)$ on the concentration of the dopant donor impurity in $\mathrm{Cd}_{0.9} \mathrm{Zn}_{0.1}$ Te-based detector.

Dashed dependences are for the composition experimentally determined in [13]; solid curves are for the same composition, but with introducing of a deep donor with an energy $E_{C^{-}} 0.79 \mathrm{eV}$ and concentration of $1.5 \cdot 10^{16} \mathrm{~cm}^{-3} ; 1,2$ - initial samples; 3,4 - after irradiation by $2 \mathrm{MeV}$ proton fluence of $6 \cdot 10^{13} \mathrm{p} / \mathrm{cm}^{2}$

In conclusion, we consider one of the results obtained in [13], the authors of which investigated radiation damage by the photoluminescence method, and the concentration of defects, their level energies and capture cross sections were determined using the thermally stimulated current (TSC) technique. The values of resistivity and gamma spectra of detectors based on the material under study was not presented in that paper. Modeling the electrophysical properties, with taking into account the parameters experimentally determined in [13] and presented there in Table, showed that it is problematically to create an acceptable gamma radiation detector based on such a material, since the maximum possible resistivity at room temperature does not exceed $10^{9} \Omega \cdot \mathrm{cm}$, which is clearly insufficient for $\mathrm{Cd}_{0.9} \mathrm{Zn}_{0.1}$ Te-based detector. In addition, this value of $\rho$ can be achieved only in a very narrow range of concentrations of the doping shallow donor from $2.47 \cdot 10^{16}$ to $2.51 \cdot 10^{16} \mathrm{~cm}^{-3}$, which requires samples with very uniform properties and the need for very precise control of dopant and defect composition. Finally, in the indicated narrow high-resistance region, the conductivity of the detector material turns out to be electronic with $n / p \sim 10^{3}$ at room temperature, although the materials for gamma and X-rays detectors have to be of hole conductivity. Modeling has shown that to eliminate the indicated drawbacks it is sufficient to introduce into the matrix a structural defect or impurity, with a deep donor level located in the band gap within the range from 0.75 to $0.80 \mathrm{eV}$. This is demonstrated in Fig. 6 which shows the dependences of the resistivity $\rho$ and the charge collection efficiency $\eta$ on the concentration of the shallow donor for the initial and irradiated samples from paper [13] (curves 1, 3), as well as with introduced deep donor having energy level at $0.79 \mathrm{eV}$ measured from the bottom of the conduction band and a concentration of $1.5 \cdot 10^{16} \mathrm{~cm}^{-3}$ (curves 2, 4). The antisite defect $\mathrm{Te}_{\mathrm{Cd}}$ can act as such a donor.

In Fig. 6 there is a noticeable shift in the dependences of $\rho\left(N_{d}\right)$ and $\eta\left(N_{d}\right)$ after irradiation towards lower concentrations of a doping shallow donor, i.e. in the course of proton bombardment, the relative content of donor-type radiation defects increases. In other words, during proton irradiation the total content of ionized radiation defects of the donor type increases relative to overall concentration of electrically active acceptors. Such phenomenon can occur in materials with an increased content of background impurities, which interact with radiation defects - cadmium vacancies, and form complexes, neutral or with an increase in the charge number by +1 relative to the initial state of $V_{\mathrm{Cd}}^{2-}$. If this assumption is correct, then the purity of the initial $\mathrm{Cd}_{0.9} \mathrm{Zn}_{0.1} \mathrm{Te}$ should be improved.

Fig. 6 also shows a clear correlation between the region of high resistance state and high values of the charge collection efficiency $\eta$, which makes it possible to obtain a high-quality detector material, provided that a deep donor is introduced into its matrix.

\section{CONCLUSION}

The simulation results are in qualitative agreement with the experimental data of $[10,12]$.

It was found that the abrupt degradation of the detector properties after proton irradiation of the CdTe:Cl and CdZnTe materials is caused by the formation of such radiation defect as interstitial tellurium Te(I), accompanied by a jump of the Fermi level $F$ to the vicinity of the level of this defect and with a decrease in the resistivity by several orders of magnitude, and change in the conductivity from hole to n-type with noticeable reduced charge collection efficiency.

It was found for the first time that the condition for the jump in properties at the final stage of irradiation is the absence of energy levels of defects in the band gap within the range between the Fermi level positions in the initial and degraded states of detector material. It was determined for the first time that in the case of the presence of the mentioned levels, the degradation of the detector properties occurs gradually as $F$ pass by these levels with some pinning near each of them in a certain range of radiation defect concentrations. Understanding the established mechanisms of degradation of CdTe and 
$\mathrm{CdZnTe}$ under the influence of proton irradiation will contribute to the development of the technology for producing radiation-resistant detectors based on these materials.

The high purity of CdTe and $\mathrm{Cd}_{0.9} \mathrm{Zn}_{0.1}$ Te materials and the presence of a deep donor in their matrix, which can be an antisite defect $\mathrm{Te}_{\mathrm{Cd}}$ or a donor impurity, with an energy level close to the middle of the band gap, are of particular importance for producing high-resistance, radiation-resistant detectors.

\section{REFERENCES}

1. M.B.H. Breese, E. Vittone, G. Vizkelethy, P.J. Sel-lin. A review of ion beam induced charge microscopy // Nucl. Instrum. \& Methods Phys. Res. B. 2007, v. 264, p. 345-360.

2. Na Guo, Caicai Rong, Yaxu Gu, Xinyi Li, Haoyan Lu, Hailei Zhang, Yajing Zhang, Yadong Xu, Hao Shen, Wei Zhang. The establishment and performance of IBIC microscopy at Fudan University // Nuclear Inst. and Methods in Physics Research B. 2019, v. 450, p. 122-126.

3. Y. Gu, C. Rong, Y. Xu, H. Shen, G. Zha, N. Wang, H. Lv, X. Li, D. Wei, W. Jie. Effects of Te inclusions on charge-carrier transport properties in CdZnTe radiation detectors // Nucl. Instr. Meth. Phys. Res. Sect. B. 2015, v. 343, p. 89-93.

4. W.J. McNeil, D.S. McGregor, A.E. Bolotnikov, G.W. Wright, R.B. James. Single charge-carrier-type sensing with an insulated Frisch ring CdZnTe semiconductor radiation detector // Appl. Phys. Lett. 2004, v. 84, p. 1988-1990.

5. Z. Feng, H. Zhong, C.E. Seifert. A prototype three-dimensional position sensitive CdZnTe detector array // IEEE Transactions on Nuclear Science. 2007, v. 54 , p. $843-848$.

6. P. Veeramani, M. Haris, S. Pullanhiotan, D. Kanjilal, K. Asokan, S.M. Babu. Investigation of swift heavy ion irradiation effects $\mathrm{Au} / \mathrm{CdZnTe} / \mathrm{In}$ detector // IEEE Nuclear Science Symposium Conference Record R12-74. 2008, v. 39, p. 357-361.

7. P. Veeramani, M. Haris, D. Kanjilal, K. Asokan, S.M. Babu. Investigation of swift heavy ion irradiation effects in CdTe crystals // J. Phys. D: Appl. Phys. 2006, v. 39(13), p. 2707

8. A. Owens, L. Alha, H. Andersson, M. Bavdaz, G. Brammertz, K. Helariutta, A. Peacock, V. Lamsa, S.A.A. Nenonen. The Effects of Proton-Induced Radiation Damage on Compound-Semiconductor X-ray Detectors // Proceedings of SPIE High-Energy Detectors in Astronomy, 29 September 2004 (SPIE, Bellingham, WA, 2004). 2004, v. 5501, p. 403-411.

9. A. Owens, S. Brandenburg, V. Gostilo, V. Ivanov, R.W. Ostendorf, F. Quarati, L. van den Berg, E.R. van den Graaf. Assessment of the radiation tolerance of $\mathrm{CdZnTe}$ and $\mathrm{HgI}_{2}$ to solar proton events // IEEE Trans. Nucl. Sci. 2009, v. 56, p. 771-776.

10. M. Zanarini, P. Chirco, W. Dusi, N. Auricchio, A. Cavallini, B. Fraboni, P. Siffert, M. Bianconi. Radiation damage induced by $2 \mathrm{MeV}$ protons in CdTe and CdZnTe semiconductor detectors // Nucl. Instr. Meth. Phys. Res. Sect. B. 2004, v. 213, p. 315-320.
11. B. Fraboni, A. Cavallini, W. Dusi. Damage induced by ionizing radiation on $\mathrm{CdZnTe}$ and CdTe detectors // IEEE Trans. Nucl. Sci. 2004, v. 51, p. 12091215 .

12. B. Fraboni, A. Cavallini, N. Auricchio, M. Bian-coni. Deep traps induced by $700 \mathrm{keV}$ protons in CdTe and CdZnTe Detectors // IEEE Trans. Nucl. Sci. 2007, v. 54, p. 828-833.

13. Y. Gu, W. Jie, C. Rong, Y. Wang, L. Xu, Y. Xu, H. Lv, H. Shen, G. Du, X. Fu, N. Guo, G. Zha, $\mathrm{T}$. Wang. Correlated analysis of $2 \mathrm{MeV}$ proton-induced radiation damage in $\mathrm{CdZnTe}$ crystals using photoluminescence and thermally stimulated current techniques // Nucl. Instr. and Meth. Phys. Res. B. 2016 , v. 386, p. 16-21.

14. Y. Gu, W. Jie, C. Rong, L. Xu, Y. Xu, H. Lv, H. Shen, G. Du, N. Guo, R. Guo, G. Zha, T. Wang, $\mathrm{S}$. Xi. Study on the bias-dependent effects of protoninduced damage in CdZnTe radiation detectors using ion beam induced charge microscopy // Micron. 2016, v. 88 , p. 54-59.

15. A.I. Kondrik, G.P. Kovtun. Tekhnologiya $i$ Konstruirovanie v Elektronnoi Apparature. 2019, N 5-6, p. 43-50 (in Russian).

16. G.F. Knoll. Radiation Detection and Measurement 4th ed. (John Wiley \& Sons, Inc.). 2010, p. 864.

17. D.M. Hofmann, W. Stadler, P. Christmann, B.K. Meyer. Defects in CdTe and $\mathrm{Cd}_{1-\mathrm{x}} \mathrm{Zn}_{\mathrm{x}} \mathrm{Te} / /$ Nuclear Instruments and Methods in Physical Researches A. 1996, v. 380, p. 117-120.

18. R. Nan, W. Jie, G. Zha, and B. Wang. Irradiation-Induced Defects in $\mathrm{Cd}_{0.9} \mathrm{Zn}_{0.1} \mathrm{Te}: \mathrm{Al} / /$ Journal of Electronic Materials. 2012, v. 41, p. 20442049.

19. B. Fraboni, L. Pasquini, A. Castaldini, and A. Cavallini. X-ray irradiation effects on the trapping properties of $\mathrm{Cd}_{1-\mathrm{x}} \mathrm{Zn}_{\mathrm{x}} \mathrm{Te}$ detectors // Journal of Applied Physics. 2009, v. 106, p. 093713-093713-6.

20. R. Nan, T. Wang, G. Xu, M. Zhu, and W. Jie. Compensation processes in high-resistivity CdZnTe crystals doped with In/Al // Journal of Crystal Growth. 2016, v. 451, p. 150-154.

21. Rui-hua Nan, Wan-qi Jie, Gang-qiang Zha, Xuxu Bai, Bei Wang, Hui Yu. Determination of trap levels in CZT:In by thermally stimulated current spectroscopy // Transactions of Nonferrous Metals Society of China. 2012, v. 22, p. s148-s152.

22. Cs. Szeles, Y.Y. Shan, K.G. Lynn, et al. Trapping properties of cadmium vacancies in Cd1-xZnxTe // Phys. Rev. B. 1997, v. 55, N 11, p. 69456949.

23. R. Gul, A. Bolotnikov, H.K. Kim, R. Rodriguez, K. Keeter, Z. Li, G. Gu, and R.B. James. Point Defects in CdZnTe Crystals Grown by Different Techniques // Journal of Electronic Materials. 2011, v. 40, N 3, p. 274-279.

24. M. Chu, S. Terterian, D. Ting, C.C. Wang, H.K. Gurgenian, and S. Mesropian. Tellurium antisites in CdZnTe // Appl. Phys. Lett. 2001, v. 79, p. 27282730 . 


\section{ВЛИЯНИЕ ДЕФЕКТОВ, ВОЗНИКАЮЩИХ ПРИ ОБЛУЧЕНИИ ПРОТОНАМИ, НА ЭЛЕКТРОФИЗИЧЕСКИЕ И ДЕТЕКТОРНЫЕ СВОЙСТВА СdTе:Cl И CdZnTe}

\section{А.И. Кондрик}

Методом компьютерного моделирования изучены механизмы влияния радиационных дефектов, возникающих при облучении протонами высоких энергий, на удельное сопротивление $\rho$, время жизни неравновесных электронов $\tau_{n}$ и дырок $\tau_{p}$ в $\mathrm{CdTe}: \mathrm{Cl}$ и $\mathrm{Cd}_{0,9} \mathrm{Zn}_{0,1}$ Те и на эффективность сбора заряда $\eta$ работающих при комнатной температуре детекторов ионизирующего излучения на основе этих материалов. Исследовано влияние рекомбинации на глубоких уровнях радиационных дефектов на деградацию $\tau_{n}, \tau_{p}$ и $\eta$ детекторов на основе $\mathrm{CdTe}: \mathrm{Cl}$ и $\mathrm{Cd}_{0,9} \mathrm{Zn}_{0,1}$ Те. Установлены основные факторы, влияющие на резкое или постепенное снижение удельного сопротивления и эффективности сбора заряда этих детекторов при их бомбардировке протонами высоких энергий, приводящих к полной деградации их регистрирующей способности. Отмечена важная роль чистоты и концентрации глубоких доноров в исходном состоянии необлученного материала детектора.

\section{ВПЛИВ ДЕФЕКТІВ, ЩО ВИНИКАЮТЬ ПРИ ОПРОМІНЕННІ ПРОТОНАМИ, НА ЕЛЕКТРОФІЗИЧНІ ТА ДЕТЕКТОРНІ ВЛАСТИВОСТІ CdTе:СІ I CdZnTe}

\section{O.I. Кондрик}

Методом комп'ютерного моделювання вивчено механізми впливу радіаційних дефектів, що виникають при опроміненні протонами високих енергій, на питомий опір $\rho$, час життя нерівноважних електронів $\tau_{n} \mathrm{i}$ дірок $\tau_{p}$ у CdTe: $\mathrm{Cl} \mathrm{i} \mathrm{Cd}_{0,9} \mathrm{Zn}_{0,1} \mathrm{Te}$ та ефективність збору заряду $\eta$ детекторів іонізуючого випромінювання на основі цих матеріалів, що працюють при кімнатній температурі. Досліджено вплив рекомбінації на глибоких рівнях радіаційних дефектів на деградацію $\tau_{n}, \tau_{p}$ і $\eta$ детекторів на основі $\mathrm{CdTe}: \mathrm{Cl}$ i $\mathrm{Cd}_{0,9} \mathrm{Zn}_{0,1}$ Те. $\mathrm{Bcтановлені}$ основні фактори, які впливають на різке або поступове зниження питомого опору та ефективності збору заряду цих детекторів при їх бомбардуванні протонами високих енергій, що призводить до повної деградації їх реєструючої здатності. Відзначено важливу роль чистоти і концентрації глибоких донорів у початковому стані неопроміненого детекторного матеріалу. 